\title{
A Simple Method for Clearing and Staining Specimens for The Demonstration of Animal Skeleton
}

\author{
Muhammad Ja'far Luthfi ${ }^{1, *}$, Nyoman Puniawati Soesilo ${ }^{2}$ \\ ${ }^{1}$ Department of Biological Education, Faculty of Science \& Technology UIN Sunan Kalijaga Yogyakarta, Indonesia \\ ${ }^{2}$ Faculty of Biology, Universitas Gadjah Mada Yogyakarta, Indonesia. \\ Author correspondency*: \\ jafarluthfi@yahoo.com
}

\begin{abstract}
Teaching skeletal system would be more attractive using real/preserved specimen compared to those using only book. The aim of the research was to develop clearing and staining method of animal skeleton specimen using Alizarin Red S-Alcian Blue as teaching aid tool. The specimen were eviscerated, fixed, stained, cleared, and keep in glycerine solution. The spesimen will increase effectiveness in elementary school science teaching and learning.
\end{abstract}

Keywords: skeleton; Alizarin Red S; Alcian Blue; elementary school; teaching aid

\section{INTRODUCTION}

Skeleton is a supporting system for vertebrate bodies. Skeleton serves to give shape and support the body, as a means for movement, as a protector of internal organs and delicate organs (blood vessels and nerve tissue), and as a place for muscle attachment. Skeleton is divided into axial skeleton and appendicular skeleton. The axial skeleton consists of skull and vertebrae (spine), while the appendicular skeleton consists of bones in the fore limbs and hind limbs (Kardong, 2002). Vertebrates are animals that have an endoskeleton and from one of its components the name is taken (vertebra/spine).

The skeletal system is one of the subject taught in high school. This material is usually taught by using books or pictures. However, according to Prokop et al (2007), teaching skeletal systems will be more attractive if using original specimens or preserved material compared to books. Direct observation plays an important role in students' understanding of biological phenomena. Students' mental models of a biological phenomenon are strongly influenced by the learning process (Prokop et al, 2007).

The National Science Education Standards in the USA emphasize that scientific inquiry is the basis of science education, where students at all levels should have the opportunity to conduct scientific inquiry. Experiments are not only provide information about an organism's system, but can also develop the ability to observe, think critically and experimentally. Students who follow the science process will better understand science concepts, appreciate how science concepts are discovered, and enhance the skills needed to investigate nature (Greene \& Greene, 2001; Newman et al., 2004).
Clearing and staining of the skeleton aims to demonstrate bone structure and cartilage in animals (Erdogan et al., 1995; Inouye, 1976). This method is commonly used in the field of teratology to study fetal defects. In teratological studies, experimental animals used are rat and mouse embryos. Since bone tissue and cartilage in embryos and in adult animals are similar histologically, and so do the small vertebrates and the large ones, theoretically the method for mouse embryos can be applied to demonstrate skeletons in adult animals or in larger vertebrates (Junquiera \& Carniero, 1988; Leeson \& Leeson, 1981). From its ability to demonstrate bone and cartilage structure, this method has the potential to be applied for developing skeletal learning media.

The method described in this article is a procedure for clearing and staining animal skeleton specimens using Alizarin Red S-Alcian Blue as a tool in teaching the skeletal system. the procedure can be followed by students themselves.

\section{MATERIALS AND METHODS}

The animals used in this study were goldfish (Cyprinus carpio), oriental whip-snake (Ahaetulla prasina), skink (Mabouya multifasciata), turtle (Trachemys scripta elegans), and flying dragon (Draco volans). The equipments used in this study were surgical scissors, scalpels, tweezers, and glass jars. The chemical used in this study were Alizarin Red S-Alcian Blue, ethanol, acetone, aquades, glacial acetic acid, glycerin, and $\mathrm{KOH}$.

The method is a modification of the Inouye (1976) originally used for small vertebrates/embryo. Inouye is 
one of the first researchers that successfully use the method for bones and cartilage staining. This is a double staining method for bone and cartilage of mice for teratological studies. Using this method, cartilage stained blue, bone stained red, whereas muscles and other tissues become transparent. Preparations for animal larger than mice and not embryos will need modification of a more massive skin and muscle removal, additional fixation time, fat removal, and extensive clearing and staining due to the thickness and robustness of tissue of mature and larger vertebrates.

Clearing and staining specimens (carp, snake, gecko tail, turtle tail, flying dragon) include several stages. The first step is exfoliation. After the scales were removed, the specimens were fixed in a tube containing 95\% alcohol for 3 days. Then the skin and muscles in the specimen are removed using scissors, tweezers and scalpel. Then fixed again in $95 \%$ new ethanol for 3 days. To remove fat, the fixed specimen was immersed in a tube containing acetone for 4 days with the replacement of new acetone on the second day. After that the specimens were immersed for 5 days in a dye solution at $37^{\circ} \mathrm{C}(1$ volume $0.3 \%$ Alcian Blue in ethanol $70 \%+1$ volume $0.1 \%$ Alizarin Red S in $95 \%$ ethanol +1 volume glacial acetic acid +17 volume ethanol $70 \%$ ). The specimens were washed in water and then immersed in a solution of $1 \% \mathrm{KOH}$ for 5 days (to make it transparent) and then soaked in succession of a mixture of glycerin and $1 \% \mathrm{KOH}$ at a ratio of $20 \%: 80 \%$; $50 \%$ : $50 \%$; $80 \%$ : $20 \%$. Finally, the specimen were stored in pure glycerin.

\section{RESULTS AND DISCUSSION}

This research has successfully develop method for clearing and staining animal skeleton specimens with Alizarin Red S-Alcian Blue (figure 1, figure 2, figure 3, figure 4 and figure 5).

Figure 1 shows a carp skeleton. The preparation shows the bones of the skull, vertebrae (backbone), and the ray fin of tail of fish that are suitable for live in water. Figure 2 is skeleton specimen of oriental whipsnake. The snake specimens show a special adaptation of vertebrate skeletons, that is, very large numbers of vertebrae $(+300$ vertebrae) suitable for terrestrial life without limbs. Figure 3 shows a skink's tail skeleton. The preparation shows the structure of the tail's vertebrae that can autotomized. Figure 4 shows a turtle's tail skeleton. Figure 5 shows the skeleton of flying dragon. The turtle and flying dragon specimens show the structure of the tail vertebra in animals that cannot be autotomized.

Using these specimens, students can directly observe the structure of the real specimen, can figure out its morphology, know the difference in structure related to its function, and gain direct experience about the skeleton. Students can more easily understand the way of life and movement of snakes and the appearance of their elongated morphology by looking at the structure of the snake's vertebrae and its enormous number of segments compared to fish. Likewise, students will be able to understand the relationship between structure and function, where an autotomized tail has a fracture plane in its vertebrae while animals that cannot autotomy do not have a fracture plane in their tail vertebrae. According to Eshach \& Fried (2005), in science learning real specimens have advantages compared to sketches, drawings, or books. Real specimens will attract more students. In addition, original specimens have the advantage of 3-dimensional detail that is not possessed by sketches or photographs. While skeleton props often do not have the details according to the original preparation.

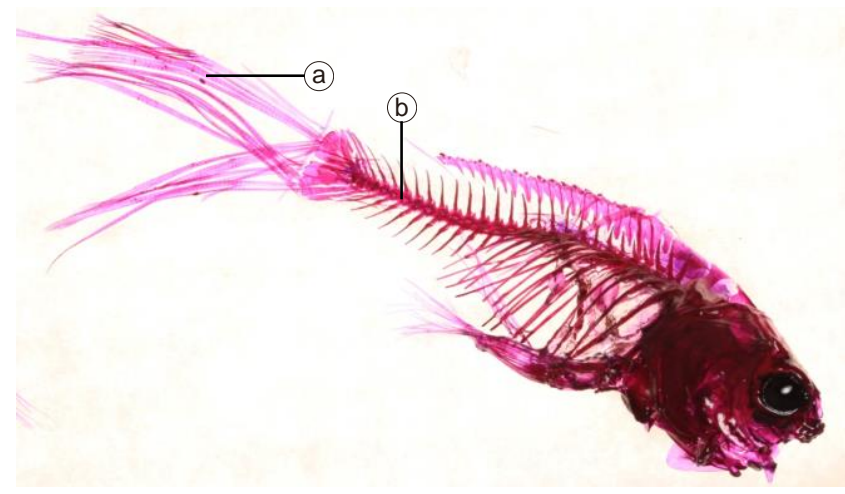

Figure 1. Structure of a carp skeleton. Visible skull bones, spine, and rays of fish tails. (a) Tail rays; (b) Vertebra.

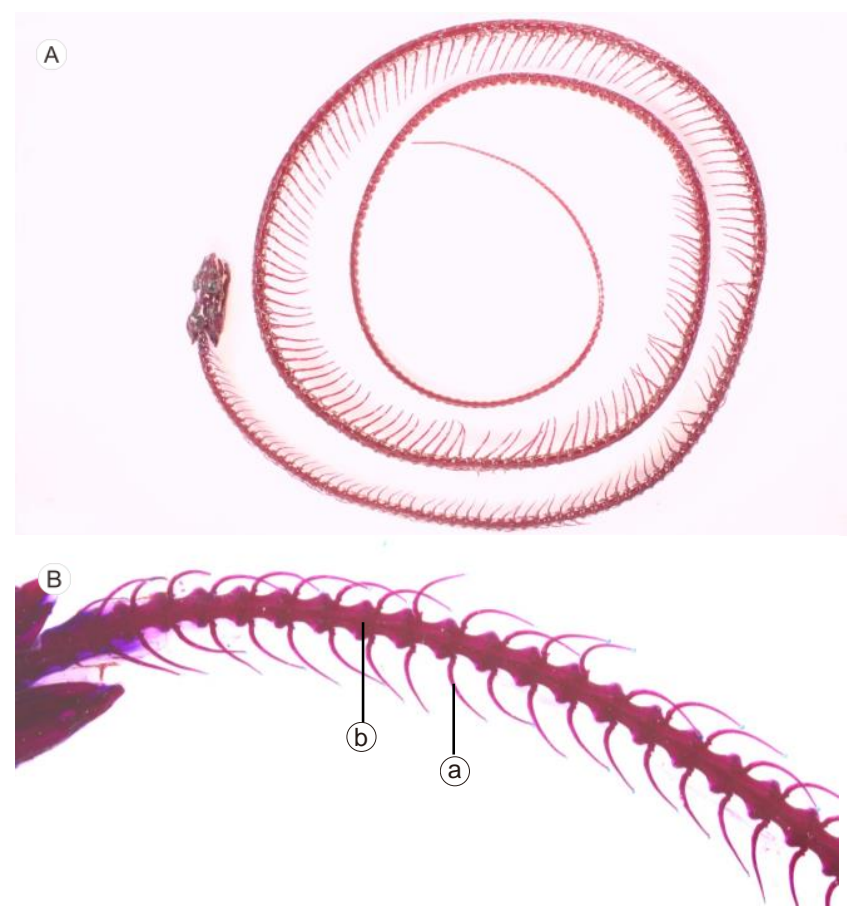

Figure 2. (A) Complete view of snake skeleton. (B) Higher Magnification. Skeletal structure of an oriental whip-snake. There are skull bones, vertebrae with very large amounts of ribs. Note the spine with ribs. (a. Ribs; b. Vertebra). 

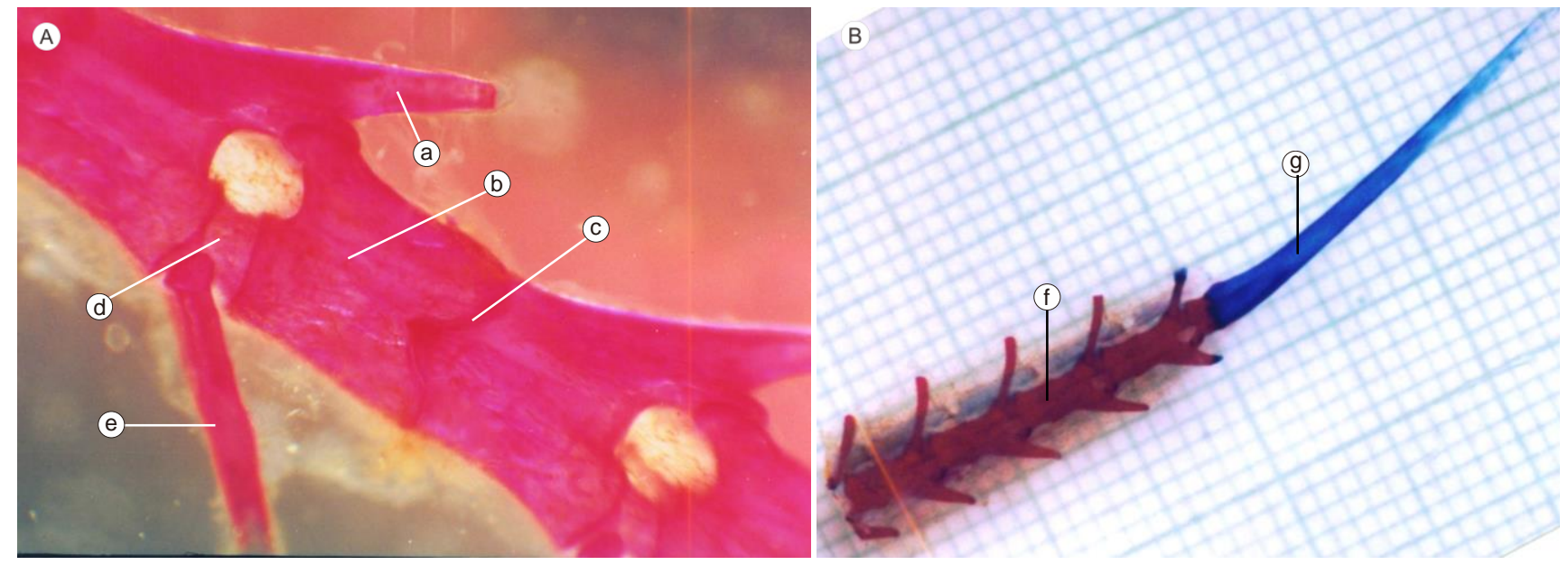

Figure 3. (A) Skink's tail skeleton structure. Visible vertebrae/tail bones with their processes. Note that there are fracture plane in the bone where the tail breaks off during an autotomy. (B) Skeleton of regenerated skink tail. After autotomy, skink will develep regenerated tail which the cartilaginous tube (stained blue) supporting tail instead of bony vertebrae. (a. Neural spine; b. Centrum; c. Fracture plane; d. Intervertebral pad; e. Chevron bone; f. Vertebra; g. Cartilaginous tube).

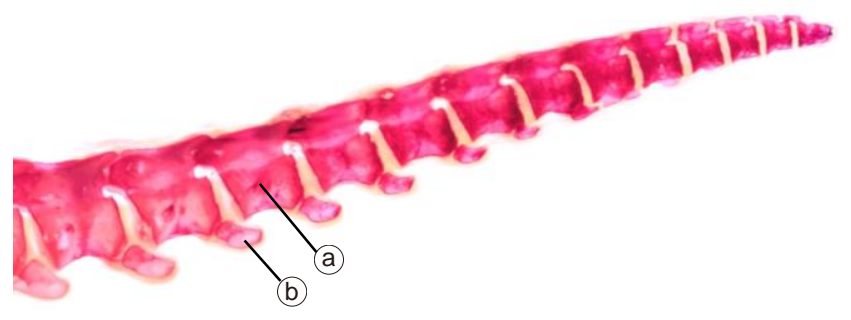

Figure 4. High magnification of the turtle tail skeleton structure. The tail consists of a series of vertebrae with their processes. The turtle's tail cannot autotomy and therefore the turtle's tail vertebrae do not have a fracture plane. (a. Centrum; b. Chevron bone).

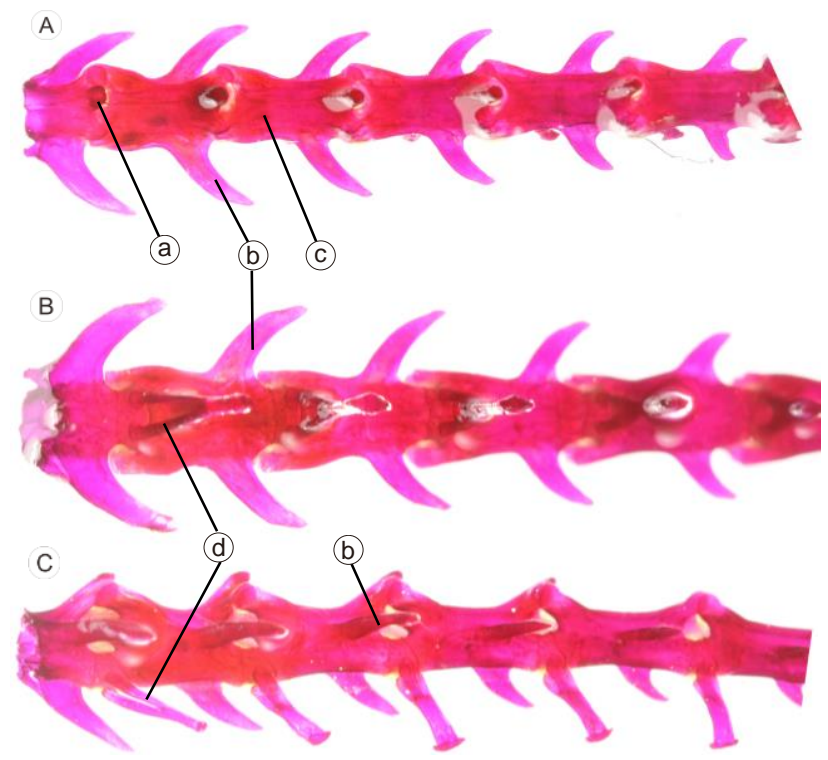

Figure 5. High magnification of the flying dragon tail skeleton structure. The tail consists of a series of vertebrae with their processes. The flying dragon tail cannot autotomy and therefore do not have a fracture plane. (A). Dorsal view. (B). Ventral view. (C). Lateral view. (a. Neural spin; b. Tranverse process; c. Centrum; d. Chevron bone).
The results show clearly visible bone structure in goldfish, oriental whip-snake, gecko tails, flying dragon tail and turtle tail. The bones stained red while the cartilage stained blue. Muscle and connective tissue become transparent/clear by the clearing process using $\mathrm{KOH}$. In these preparations the details of the skeleton can also be observed such as the processus of the vertebrae, intervertebral discs, ribs, fracture plane, and other details.

Figure 1 shows a fish's skeleton. Students can observe the presence of skull bones in fish, vertebrae, and fin rays of fish. From these specimens, it is known that the fin rays of the fish are composed of bone material. From the snake preparation (figure 2) we can observe the structure of the snake vertebrae that has ribs on its body vertebrae. Only in the tail, the snake vertebrae do not have ribs. The ribs serve as muscles attachment and help the movement of snakes. The skink tail (figure 3), turtle tail (figure 4) and flying lizard tail (figure 5) provide structures that are ideal for studying skeleton anatomy, and to some extend student can learn the relationship between form and function. Skink's tail can autotomized its tail, whereas the tail of a turtle and flying lizard cannot autotomy. This functional difference is also reflected by differences in structure, namely the existence of fracture plane in the skink tail vertebrae. It is on these fracture planes that the tail can break. This autotomy ability is a form of gecko's self-defense to avoid predator. Turtles and flying lizard cannot autotomized its tail so that it can be understood if there are no fracture plain in the vertebrae. Adapting its way of life, the tail of the flying lizard is needed to help the movement on the tree and when it gliding. Therefore, breaking the tail would certainly be less profitable. The same is true for turtles. Turtles have very hard carapace and plastrons. If there is a threat or an enemy, the turtle 
will insert its head and motion apparatus into the carapace and plastron.

Learning in this way will be more interesting for students. This bone specimen makes it easier for students to understand skeletal structure. Understanding the anatomical structure will facilitate the understanding of its function. Students will be able to observe the components of the skeleton, the skeleton differences in its way of life, the skeleton differences between animal classes, and the relationship between structure and function (a given structure reflects certain function). In addition, using real specimens will be more interesting for students related to their 3-dimensional shapes, attractive colors, and direct experience of seeing original specimens from a visual, tactile and motoric perspective.

Appleton (2008) stated that often school teachers are hesitant in teaching science. The main reason is the limited knowledge of teachers about science content. This paper provides a teaching of animal skeleton by directly involving teachers and students in the science process so that they can see directly the science process. Thus the confidence of teachers and students will arise to learn science. Matthews et al (1997) stated that students have a high curiosity about the world around them, and nature offers a variety of materials in which the teacher becomes a mentor to help students to satisfy their curiosity by studying the natural surroundings.

This study used local animals that are widely found around us, namely, goldfish/carp (Cyprinus carpio), oriental whip-snake (Ahaetulla prasina), gecko (Gecko gecko), turtle (Trachemys scripta elegans), and flying dragon. This certainly makes it easier for teachers to develop science learning media in accordance with school availability and abilities. This is in accordance with the opinion of Matthews et al (1997) which stated that nature provides the appropriate material to satisfy students' curiosity that is so high towards the natural surroundings.

According to Eshach \& Fried (2005), the superiority of the real specimens for learning as mentioned above is very suitable for children's learning. Children (including elementary school students) have a high curiosity. This character is very suitable for science considering that one of the factors driving science is curiosity. Children really like to observe and think about the environment. Exposing scientific processes to young persons will develop positive attitudes towards science (Eshach \& Fried, 2005; Appleton, 2008). Greene et al (1993) stated that real specimens are very important in many aspects of cognitive learning in the classroom.

In this study the most important aspect in the success of staining is skin and muscle removal, and the stages of fixation. The skin and muscles must be removed as much as possible so that only a little muscle remains for the attachment of each bones. But it should be noted that skin and muscle removal should not cut the bone/skeleton itself. The vertebrae have many processes.
Often during the removal of skin and muscles, the process of the vertebrae is unintentionally cut off. This will certainly change the vertebral morphology caused by the artifact, as a result of error in cutting.

Fixation and fat removal were done longer than the Inouye method, because the structure of the skin and muscles of the mature animals are thicker and stronger than the embryo so that the fixative solution takes longer to penetrate the tissue. Different specimens require different time periods for fixation, fat removal, clearing and staining. This depends on the species, maturity (embryo or adult), body size, and organs/body parts made for preparations. In general, larger and more mature animals require a longer period of fixation, fat removal, clearing and staining. The length of time for fixation, fat removal, clearing and staining in this study can be used as a guide in staining for other animals.

This research has succeeded in developing a skeleton (bone and cartilage) staining method for learning skeleton systems for high schools. Learning in this way will involve the teacher and students in the science process. In addition, the use of real specimens will make it easy to understand the skeleton stucture and more attractive to students. The process and materials needed in this study are very simple, and can be applied to other local animals that are available according to the availability in the environment around the school.

\section{CONCLUSIONS}

The study of organisms including the skeletal structure is an important part of the basic education science curriculum. The use of pictures, sketches, visual aids, and books to explain the skeletal structure is a common method used in the teaching of skeletal systems. However, this method often causes less student interest. The skeleton system is also more difficult to understand with the use of instructional media. The author provides alternative for high school teachers in teaching the skeletal system. Making skeletal preparations by involving students is not commonly carry out in the learning of primary school framework systems, but teachers can combine them with the existing curriculum to expand the scope of basic education.

\section{ACKNOWLEDMENTS}

The authors would like to thank the assistants of Animal Anatomy Lab Work at the Faculty of Science and Technology of UIN Sunan Kalijaga, members of the Apprenticeship Program at the Faculty of Science and Technology of UIN Sunan Kalijaga, and members of the Center for Integrative Zoology of UIN Sunan Kalijaga for their role to make this research possible. The authors also would like to thank to Mr. Riyanto (staff of the Faculty of Science of Technology) for his assistance in pictures processing. 


\section{REFERENCES}

Appleton, K. 2008. Developing Science Pedagogical Content Knowledge Through Mentoring Elementary Teachers. J Sci Teacher Educ 19: 523-545.

Erdogan, D., Kadioglu, D., Peker, T. 1995. Visualization of the Fetal Skeletal System by Double Staining with Alizarin Red and Alcian Blue. Gazi Medical Journal 6: 55-58.

Eshach, H., Fried, M. N. (2005). Should science betaught in early childhood? Journal of Science Education and Technology, 14: 315-336.

Greene, J.S., B.D. Greene. 2001. Using Amphibians and Reptiles to Learn the Process of Science. Science Activities 37 (4): 29 32.

Greene, E. A., K. R. Smith, J. S. Pendergraft, R. H. Raub, and, M. J. Arns. 1993. Technical Note: Equine Skeletal Preservation Techniques to Enhance Teaching Effectiveness'. Journal of Animal Science. 71:2270-2274.

Inouye, M. 1976. Differential Staining of Cartilage and Bone in Mouse Skeleton by Alcian Blue and Alizarin Red S. Congenital Anomalies 16: 171-173.
Junquiera, L.C. \& Carneiro, J. 1988. Histologi dasar. Terjemahan. Edisi ke-3. EGC penerbit buku kedokteran. Jakarta.

Kardong, K. V. 2002. Vertebrates Comparative Anatomy, Function, and Evolution. International Edition. Third Edition. McGraw-Hill Higher Education. New York. USA. hal: 233236.

Leeson, T. S., \& C.R. Leeson. 1981. Histology. Fourth edition. W.B. Saunders Company. Philadelphia. 514-534.

Matthews, R.W., L. R. Flage, and J. R. Matthews. 1997. Insects as Teaching Tools in Primary and Secondary Education. Annual Reviews of Entomology 42:269-89.

Newman, W.J., S. K. Abell, P.D. Hubbard, J. McDonald, J. Otaala, M. Martini. 2004. Dilemmas of Teaching Inquiry in Elementary Science Methods. Journal of Science Teacher Education 15(4): 257-279.

Prokop, P., M. Prokop, S.D. Tunnicliffe, C. Diran. 2007. Children's ideas of animals'internal structures. JBE 41 (2) 62-67 
THIS PAGE INTENTIONALLY LEFT BLANK 